\title{
Prosodic and lexical marking of contrast in L2 Italian
}

\author{
Giuseppina Turco \\ Universität Stuttgart, Germany \\ Christine Dimroth \\ Universität Münster, Germany
}

Bettina Braun

Universität Konstanz, Germany

\begin{abstract}
We investigated the second language (L2) acquisition of pragmatic categories that are not as consistently and frequently encoded in the L2 than in the first language (LI). Experiment I showed that Italian speakers linguistically highlighted affirmative polarity contrast (e.g. The child ate the candies following after The child did not eat the candies) in $34.3 \%$ of the cases, by producing a nuclear pitch accent on the finite verb (i.e. verum focus accent). Experiment 2 revealed that high-proficient German and Dutch non-native speakers of Italian linguistically encoded polarity contrast more frequently, either using a verum focus accent (German) or lexical markers (Dutch). This corresponds closely to the patterns preferred in their native languages. Our results show LI transfer on three levels: (I) the relevance of the pragmatic category (i.e. marking polarity contrast on the assertion component), (2) the linguistic markers to encode polarity contrast and (3) the phonetic implementation of the intonational marking. These three levels of transfer have implications for how non-native speakers acquire the $L 2$ discourse organizational principles and the linguistic markers to encode them.
\end{abstract}

\section{Keywords}

polarity contrast, LI transfer, intonation, information structure

\section{Introduction}

Learning a second language in adulthood requires the acquisition of the set of linguistic expressions of the target language (L2) and the pragmatic contexts in which certain

\section{Corresponding author:}

Giuseppina Turco, Universität Stuttgart, Institut für Linguistik: Anglistik, Keplerstr 17 70174, Stuttgart, Germany.

Email: giuseppina.turco@ifla.uni-stuttgart.de 
forms are used. Assuming for the moment that information structure categories like topic and focus are universal and that linguistic expressions are language-specific, adult nonnative speakers can use their prior knowledge of these functions (but not necessarily their encoding) when acquiring an L2. However, across languages, not all pragmatic categories are equally explicitly encoded on the same level (Matić and Wedgwood, 2013). One such case is affirmative polarity contrast, ${ }^{1}$ i.e. a focus on the polarity of an utterance in contexts where speakers assert a claim that was previously denied (e.g. The child ate the candies following after The child did not eat the candies). Recent empirical studies (Dimroth et al., 2010; Turco et al., 2014) have revealed that focusing affirmative polarity plays a crucial role for common ground management ${ }^{2}$ (Krifka and Musan, 2012) in the Germanic languages German and Dutch but not in the Romance languages French and Italian. It is probably not a coincidence that the grammar and the lexicon of Germanic languages provide speakers with a rich inventory of linguistic expressions to encode polarity contrast and, more specifically, contrastive pitch accents on the finite verb ('verum focus accent', henceforth) and sentence-internal affirmative particles (e.g. Dutch wel, German doch, schon, wohl, roughly meaning 'indeed'). Turco et al. (2014) tested how German and Dutch speakers encode polarity contrast by means of a picture-difference task. In this experimental setting, a switch on the polarity was related to two different (topic) situations (Klein, 2008). These two topic situations were experimentally controlled by providing two different pictures (speaker A: [In my picture $]_{\text {TopicSituation } 1} X$ is $[\text { not }]_{\text {polarity }}$ doing $Y$; speaker B: [In MY picture $]_{\text {TopicSituation } 2} X[i s]_{\text {polarity }}$ doing Y). This scenario resulted in a double contrast (e.g. a switch on the topic and on the polarity) rather than a correction (i.e. a switch on the polarity only, so that opposite propositions are mutually exclusive). The analysis of productions revealed that, despite the presence of such a double contrast, speakers of both languages consistently highlight the change in polarity (Dimroth et al., 2010; Turco et al., 2014). However, the linguistic encoding is different: while German speakers mostly produce a verum focus accent (e.g. Das Kind HAT die Bonbons gegessen 'the child DID eat the candies'), Dutch speakers predominantly encode polarity switch with the stressed variant of the affirmative particle wel (e.g. Het kind heeft de snoepjes WEL ${ }^{3}$ opgegeten 'the child did INDEED eat the candies'). Crucially, both types of markers (i.e. verum focus accent and affirmative particles) are affecting the utterance's polarity (for more details, see Appendix 1).

In the Romance languages Italian and French, on the other hand, the pragmatic category of polarity contrast does not seem to be equally relevant (Dimroth et al., 2010; Turco et al., 2011, 2013). Previous experiments have provided a first set of data on how contexts with a switch on the polarity comparable to the ones described above are verbalized in Italian (Dimroth et al., 2010; Turco et al., 2011). For instance, evidence from free narrative productions (Dimroth et al., 2010) shows that Italian speakers who retell events shown in a film prefer to explicitly encode the contrast on the topic (e.g. Il signor Blu $\dot{e}$ l'unico a buttarsi, 'Mr Blue is the only one to jump') but not on the polarity (as is done in Dutch or German, e.g. Herr Blau SPRINGT, 'Mr Blue JUMPS'). The same contrastive relation between subsequent propositions can hence be expressed by highlighting different information structure units across languages, i.e. the topic in Italian, the polarity in German and Dutch (Dimroth et al., 2010). 
These typological differences raise the question of whether highly proficient nonnative (L2) speakers eventually learn to highlight the target-like information structure unit. In this article, we particularly investigate how non-native speakers encode the information flow when pragmatic categories like polarity contrast, which play a crucial role in their first language (L1), are not relevant for discourse organization in their target language. To this end, we will examine L2 speech productions from high-proficient German and Dutch non-native speakers of Italian (Experiment 2) and compare it to that of native speakers of Italian (Experiment 1) and to that of German and Dutch natives (results published in Turco et al., 2014). For the sake of clarity, contexts containing a switch on the polarity will be referred to as 'polarity-switch contexts', whereas linguistic expressions that highlight a contrast on the polarity component as 'polarity contrast markers'.

Effects of typological differences on the L2-encoding of information structure in high-proficient non-native speakers have already been investigated in a number of linguistic domains, such as temporality, space and referential movement (e.g. Carroll and Lambert, 2006; Carroll et al., 2000; Hendricks and Hickmann, 2011; von Stutterheim and Lambert, 2005) including the pragmatic category of polarity contrast (Benazzo et al., 2012). In particular, by using the film-retelling elicitation procedure as in Dimroth et al. (2010), Benazzo et al. (2012) found that German non-native speakers of Italian or French tend to recruit lexico-grammatical marking that highlight the polarity component, which is more in line with their L1 perspective. On the whole, findings in that study provide a first piece of evidence that L1 transfer can also affect the relevance of a pragmatic category, but more data are needed to substantiate this claim. The current article provides a first step in this direction.

A further level of transfer concerns the actual linguistic markers that are recruited. Since we focus on two specific language-pair configurations (German and Dutch speakers of L2 Italian), it is expected that non-native speakers will use equivalent lexical markers (e.g. polarity particles) and/or intonational markers (i.e. verum focus accent) in polarity-switch contexts as in their respective native languages. Previous L2 studies on particles have mainly investigated whether non-native speakers acquire the target-like functions of the particles in cases when the L1 and the L2 share the same inventory (such as German and Dutch; see Hogeweg et al., in press), or whether non-native speakers with an L1 that has fewer or no particles acquire such new forms and their respective functions in the L2 (Caspers and van der Wouden, 2008; Möllering, 2001; Möllering and Nunan, 1995). To our knowledge, little or no attention has been paid to explore what non-native speakers do when the L2 does not provide them with equivalent devices that are widely available and as frequently used as in their L1. As far as L2 intonation is concerned, previous studies have found that when marking information structure, non-native speakers transfer their L1 focus-projection rules (e.g. Zubizaretta and Nava, 2011) and the L1 intonational patterns, even at a high level of proficiency (Kelm, 1987; McGory, 1997; Nguyên et al., 2008; Rasier and Hiligsmann, 2007; Swerts and Zerbian, 2010; Ueyama and Jun, 1998, among others). From the literature on L2 intonation, it is also well established that L1 transfer can affect more fine-grained aspects of the prosodic structure, such as the phonetic implementation of identical phonological pitch movements (e.g. Atterer and Ladd, 2004; Gut, 2009; Mennen, 2004). 
In sum, previous L2 studies have either investigated the acquisition of cognitive categories like space and time for discourse cohesion, or the level of the linguistic realization (e.g. use of lexical or prosodic markers, phonetic implementation). Here we look at whether high-proficient L2 speakers manage to select and highlight the target-like information structure unit. We investigate this aspect in a language, Italian, in which polarity contrast does not seem to be as consistently and frequently highlighted as in the L1 (see Dimroth et al., 2010).

This article is structured as follows: the first part shows findings from a controlled production study on Italian polarity marking. While Dimroth et al.'s study (2010) provides a general picture of whether and how Germanic and Romance languages encode polarity contrast in free productions, more empirical evidence is necessary to understand what Italian speakers do when they are encouraged to explicitly draw the interlocutor's attention to a change in polarity (for a first data-driven investigation, see Turco et al., 2011). For a direct comparison to the findings reported for German and Dutch speakers in Turco et al. (2014), we adopt the picture-difference task here as well (Experiment 1). Given that the intonational phonology of Italian strongly varies across dialects (see D'Imperio, 2002 and references therein), we restrict our investigation to one regional variety, the one spoken in Rome. In the second part of the article, we focus our attention on the acquisitional aspects of polarity contrast. Using the same elicitation procedure as for Italian native speakers, we test high-proficient German and Dutch speakers of L2 Italian who had been living in Rome for several years. In particular, we investigate whether they eventually discover that Italian native speakers do not consistently rely on polarity contrast but also prefer other discourse units in order to establish discourse coherence (Experiment 2).

\section{Focus marking in Italian}

It is a well-known fact that Italian - like other Romance languages - uses particular syntactic constructions, such as clefts or left dislocations, to signal different information structures, such as contrastive focus (e.g. Il LIBRO, ti porterò domani (non altre cose) 'I will bring you the BOOK tomorrow (and not other things)') (e.g. Antinucci and Cinque, 1977; Belletti, 2009; Benincà, 1993; Benincà et al., 1988; Bocci, 2014; Rizzi, 1997).

Contrastive focus can be also expressed in situ by controlling the location of the nuclear accent (D'Imperio, 2002; Face and D'Imperio, 2005). In a declarative with a broad focus, default rules of stress assignment predict that the nuclear stress is located on the rightmost metrical head of the utterance, i.e. Mamma andava a ballare da LALLA, 'Mom used to dance at Lalla's' (i.e. the 'Designated Terminal Element', e.g. Ladd, 2008; Nespor and Vogel, 1986), whereas in a declarative with a contrastive focus, the nuclear stress can shift onto the focused (lexical) word (e.g. Mamma andava a BALLARE da Lalla, 'Mom used to dance at Lalla's', D'Imperio, 2001; Grice, D'Imperio, Savino, and Avesani, 2005). ${ }^{4}$

In most regional varieties of Italian, the size of the focus domain can be disambiguated by different pitch accent types. ${ }^{5}$ In a declarative with a broad focus, the pitch accent type for the nuclear accent position is the falling $\mathrm{H}+\mathrm{L}^{*}$ tone (Frascarelli, 2004; Giordano, 2004; Sardelli, 2006). In a declarative with a contrastive focus, the nuclear 
pitch accent can be either $\mathrm{H}^{*} \mathrm{~L}$ - (i.e. with the $\mathrm{H}^{*}$ realized on the stressed syllable and the $\mathrm{L}-$ on the post-nuclear syllable of the focused element) or $\mathrm{H}^{*}+\mathrm{L} \mathrm{L}-\mathrm{L} \%$ (i.e. with the fall realized within the nuclear syllable of the focused element) in Roman Italian (see Frascarelli, 2004).

One interesting aspect in Italian phonology is the option to accent informationally given (post-focal) elements under certain structural (syntactic) conditions. For instance, while in Italian deaccentuation of full noun phrases and (subordinate) clauses is possible, such as the (underlined) subordinate Guglielmo non beve perché é infelice ('Guglielmo does not drink because he is unhappy', e.g. Farnetani and Zmarich, 1997; Hirschberg and Avesani, 1997), deaccentuation of given elements within full noun phrases does not seem to be an option (for experimental evidence, see Swerts et al., 2002). This phenomenon is described as lack of 'contextual deaccenting' within syntactic phrases (Ladd, 2008; Rooth, 1996). The picture is not clear-cut, however: For Siena Italian, Bocci (2014) observes that post-focal words are always metrically phrased and headed and are therefore, marked by a L* accent in ToBI-style annotation (Grice et al., 2005). For Southern varieties, a compressed ('downstepped') pitch movement (i.e. ! $\mathrm{H}+\mathrm{L}^{*}$ ) is also attested for similar purposes (Grice et al., 2005). Despite the presence of these postnuclear accents, the most salient and prominent pitch accent is the one on the informationally focused word (i.e. the nuclear pitch accent, which is 'the rightmost fully-fledged pitch accent in the focused constituent', D'Imperio, 2001; Grice et al., 2005: 380).

To date, we still know very little about how utterances in which the polarity switches from negation to affirmation are expressed in Italian. Regarding lexical markers, it has been claimed, for instance, that Italian uses cleft constructions with a left-fronted polarity marker such as sì che or invece sì (e.g. speaker A: Io non bevo - speaker B: Sì che bevi, meaning: speaker A: 'I don't drink' - speaker B: 'You do drink', Bernini, 1995: 184; Poletto and Zanuttini, 2013). In both studies the reported examples represent cases of correction (see Section I): sì che reverts the truth value and, similarly, invece sì indicates speaker's disagreement to what was just claimed. When a topic switch is present, in addition to a polarity switch (e.g. $[\mathrm{Mr} \text { Blue }]_{\text {Topic1 }}$ does not jump $>[\mathrm{Mr} R e d]_{\text {Topic } 2}$ does jump), previous experimental work attests the presence of the sentence-initial adverb invece (roughly meaning 'on the other hand'; see Dimroth et al., 2010) and - though rarely - intensifiers like proprio, effettivamente (roughly meaning 'certainly'; see Dimroth et al., 2010). These markers do not seem to specifically convey a polarity contrast (Dimroth et al., 2010).

We know even less about the intonational marking of polarity contrast and, in particular, about the possibility of signalling this pragmatic category through a nuclear pitch accent on the finite verb (Dimroth et al., 2010; Turco et al., 2011). Dimroth et al. (2010), for instance, reported no instances of verum focus accent, but only one case of focal accent on the non-finite verb (Dimroth et al., 2010; and, for similar findings on French, Turco et al., 2013; see also Turco et al., 2011). Yet, the absence of verum focus accents in these studies imply that this marking is impossible in Italian; rather, it requires a more fine-grained investigation that extends the analysis to a wider range of encoding options (lexical and intonational marking).

In addition, these studies further raise the question of whether producing a verum focus accent in Italian may partly depend on the type of finite verb (i.e. lexical or 
auxiliary/copula verb) as well as other factors such as the position of the auxiliary within the (syntactic and prosodic) phrase of analytical verb forms (e.g. ha mangiato - '( $/$ /he) has eaten'). For instance, in cases of negative polarity corrections, Ladd (2008: 233) reports that the finite verb, which precedes the negation, may receive a falling nuclear accent (i.e. non È la mia bici, 'it IS not my bike'). Following Selkirk (1995), in a verb phrase containing a monosyllabic auxiliary, the auxiliary is integrated into the prosodic structure at the level of the phonological phrase $(\varphi)$ and treated as a clitic. When focused, monosyllabic function words can appear in their strong form and have a foot-head status (Selkirk, 1995); consequently, they can be assigned a pitch accent. Yet, Selkirk's (1995) formulation of such constraints is mainly based on English. Hence, we first have to establish how focused and non(phrase)-final monosyllabic auxiliaries are tonally marked in Italian. After all, a prerequiste for a verum focus accent is that these functional elements can be focused. The literature on focus reviewed above has mostly investigated the intonational marking of focused lexical elements. Klein $(1998,2006)$ proposed a relation between finiteness and assertion, which suggests that finite verbs are the carriers of the assertion. We therefore test whether polarity switch is encoded in the same way across three different verb conditions (see also Bernini, 2009): (1) utterances containing finite lexical verbs, in which the semantic/lexical component is merged together with the assertion component; (2) analytical verb forms where the assertion and the lexical component are encoded respectively by the auxiliary and the non-finite verb; (3) constructions with copula verbs containing only the assertion component.

\section{Experiment I}

Experiment 1 tested how (Roman) Italian speakers express polarity contrast in utterances with different verb types (lexical, auxiliary and copula verbs), concentrating on the use of lexical markers (i.e. sentence-initial adverbs like sì che, (invece) sì, invece) and of intonational realizations. No clear predictions regarding the use of lexical markers are possible at this point. While the form sì che may be more specific for conveying a corrective meaning on the polarity component (Poletto and Zanuttini, 2013), invece can be used in any contrastive environment. Intensifiers like proprio, davvero are less likely to be produced in the tested specific contexts (for more details, see Dimroth et al., 2010).

Intonationally speaking, the literature reviewed above shows that in Italian pragmatic focus can be expressed in situ via nuclear accent placement. Hence, in the absence of other encoding strategies, two outcomes are possible:

1. A verum focus accent may be realized on lexical finite verbs but not on auxiliary/ copula verbs, since the latter are procliticized to the following lexical word and cannot receive an accent (Selkirk, 1995; Truckenbrodt, 1999). Assuming that such verb type differences are observed, it is conceivable that in analytical verb forms, speakers produce an accent on the non-finite verb instead, which is the phrasal head of the verb phrase (see Féry and Samek-Lodovici, 2006). Similar findings were also found for polarity-switch contexts in French: In more than $40 \%$ of analytical verb forms, French speakers realized initial accents on the first syllable of the non-finite verb along with deaccented object nouns, a realization 
that was not observed in contexts without switch on the polarity (Turco et al., 2013).

2. A verum focus accent is realized independently of verb type. In this scenario, the need to focus the carrier of the assertion is very strong (Klein, 1998, 2006; Bernini, 2009).

Note that both outcomes are compatible with Selkirk's (1995) analysis, but require a different constraint ranking. In the first case, structural constraints of the language are more important than pragmatic ones; in the second case, pragmatic constraints are more important than structural ones.

\section{Methods}

We used a picture-difference task to elicit semi-controlled productions in contexts with a switch on the polarity (i.e. polarity-switch context trials) and contexts with no switch on the polarity but with broad focus on the predicate (i.e. predicate-focus context trials) acting as controls (for a more detailed description, see Turco et al., 2013, 2014). This comparison allowed us to determine whether certain realizations are specific to polarity contrast or whether they are used in any contrastive condition. More specifically, this task elicits picture comparisons in the form of a dialogue-game between a confederate speaker and the participant. The dialogue is built on three comparable pictures:

- a baseline picture accessible to both speakers, in which a situation is illustrated and the common ground laid out (e.g. a child eating candies);

- a negation picture, in which the opposite event is depicted (e.g. the child is not eating the candies), accessible only to the confederate;

- an affirmation picture that is similar to the baseline picture (e.g. the child is eating the candies), accessible only to the participant.

By manipulating the context utterance produced by the confederate, we could elicit target utterances with the same word order but with a change in the polarity or in the predicate.

a Participants. Fourteen native speakers of Italian ( 4 male, 10 female, average age $=$ 22.7 years, $S D=2.6$ ) participated for a small fee. They were all students at the Università degli Studi di Roma La Sapienza and originated from Rome. None of the tested speakers had learned a language other than their mother tongue before the age of 10 .

b Materials. The experiment consisted of 32 polarity-switch trials, 32 predicate-focus trials (controls), and 50 filler trials eliciting other focus structures (e.g. narrow focus on other constituents of the utterance, negative polarity contrast). The 32 polarity-switch trials and the 32 predicate-focus trials consisted of:

- Lexical verbs (Lex, henceforth): Twelve trials in which pictures illustrated ongoing actions designed to elicit transitive verbs that were inflected in simple-present tense (e.g. mangia '( $\mathrm{s} / \mathrm{he})$ eats'). 
- Auxiliary verbs (Aux): Twelve trials in which pictures depicted completed actions designed to elicit telic transitive verb constructions containing auxiliary plus nonfinite verb (e.g. ha mangiato '( $\mathrm{s} / \mathrm{he}$ ) has eaten').

- Copula verbs (Cop): Eight trials with emotional state pictures that were designed to elicit a copula verb (e.g. è triste '(s/he) is sad'). ${ }^{6}$

The full list of stimuli is presented in Appendix 2.

The typical form of the utterance spoken by the confederate contained a prepositional phrase, encoding a topical contrast (e.g. Nella mia immagine - 'In MY picture' ...), followed by a Subject-Verb-Object (SVO) sentence. The finite verb was always conjugated in the third-person singular: the lexical verb was always disyllabic (e.g. mangia '(s/he) eats'); the auxiliary was always the monosyllabic $h a$ ('has'); the copula verb was always the monosyllabic $\dot{e}$ ('is'). Because of the sentence-initial prepositional phrases (i.e. Nella mia immagine ...), these utterances expressed a double contrast (contrastive topic plus polarity switch), thereby allowing for a direct comparison with similar contexts elicited in Dimroth et al.'s study (2010).

The confederate was a female speaker of (Roman) Italian (24 years old). She was instructed to seek eye contact (after having looked at her picture) and was trained beforehand to produce the same intonation contour for all participants. In polarity-switch context trials, utterances were typically realized with a high-falling nuclear accent (i.e. $\mathrm{H}+\mathrm{L} *$ L-) on the finite verb (i.e. non MANgia, '(s/he) doesn't eat'; see Ladd, 2008). In predicate-focus context trials, the confederate produced a $\mathrm{H}+\mathrm{L}^{*} \mathrm{~L}-$ nuclear accent on the grammatical object of the utterance.

c Procedure. Participants were instructed with a video-clip tutorial and familiarized with the task in a short warm-up session consisting of four trials. Each picture described a single event. To avoid ellipsis, participants were encouraged to produce one complete sentence for each picture: They were told that their productions would later be used for another game in which somebody else would have to match the corresponding pictures to their descriptions. Every trial was structured in the following way: The confederate always had the first turn. She first looked at the baseline picture (e.g. child eating the candies) and then at her own picture (negation picture: child not eating candies) and compared the two pictures. She then uttered a typical SVO sentence preceded by a prepositional phrase as in: In my picture the child is not eating the candies. Then, the participant looked at his/her picture and produced a target utterance with positive polarity.

All sessions took place in a quiet experiment room at the University La Sapienza in Rome (Italy).

d Data selection. The 448 utterances produced in polarity-switch trials were labelled on the prosodic phrase, word and syllable level using Praat (Boersma and Weenink, 2012). We discarded 148 utterances containing pauses within syntactic phrases $(n=38)$, pronouns instead of full noun phrases $(n=71)$ or grammatical verb forms different from those of the confederate (e.g. with different tenses or aspects, $n=39$ ) since this caused too much variation for prosodic analysis. This left 300 utterances for the analysis of polarity-switch contexts (103 with full lexical verbs, 117 with auxiliary verbs, 80 with 
Table I. Polarity-switch context trials: Relative frequency of mutually exclusive linguistic markers by Italian native speakers (percentages).

\begin{tabular}{lc}
\hline Linguistic markers & Italian natives \\
\hline Verum focus accent (with/without postnuclear accents) & $\mathbf{3 4 . 3}$ \\
Sentence-initial adverbs (i.e. si che, (invece) si) & $\mathbf{0 . 0}$ \\
Nuclear accent on the non-finite verb & 21.4 \\
Nuclear accent on the object (optionally with the adverb invece) & 44.3 \\
\hline
\end{tabular}

Note. Polarity contrast markers are highlighted in bold.

copula verbs). In the predicate-focus contexts, 127 trials were discarded for the same reasons as described above, leaving 321 utterances.

For the tonal description of the utterances, we used the Autosegmental-Metrical (AM) account for Italian (see Grice et al., 2005). In the AM description for Italian, nuclear pitch accents are flagged with an $n$ letter to distinguish them from post-nuclear accents. Utterances were labelled by the first author, a native speaker of Italian. To determine labelling accuracy, a random selection of $30 \%$ of the utterances (including data from all three verb types) produced in polarity-switch trials were also annotated by a German native with training in phonology and phonetics. ${ }^{7}$ We then computed the Kappa Coefficient of Agreement (Cohen, 1960). In cases of disagreement, we chose the annotation of the native speaker, the first author. All the statistical analyses were performed using R software package (R Development Core and Team, 2012).

\section{Results}

The interrater reliability score for nuclear pitch accent placement in polarity-switch contexts was found to be Kappa $=0.87(p<.0001), 95 \%$ CI $[0.70,1]$, which signals a high level of agreement (Landis and Koch, 1977).

Before showing the results regarding the polarity-switch trials, we describe how Italian speakers signalled utterances in the predicate-focus trials. Speakers produced a nuclear pitch accent on the last constituent of the utterance (i.e. the object noun) in all cases. Furthermore, predicate-focus utterances were preceded by the initial adverb invece ('on the other hand') in about $27 \%$ of these cases.

We then analysed the distribution of linguistic forms produced in polarity-switch context trials. Table 1 illustrates the type of linguistic markers that were found across trials. We also included a line for markers that are expected on the basis of previous studies. The markers are further classified into two groups:

- Polarity contrast markers (specifically highlighting the assertion component): This category includes a focal accent on the finite verb (verum focus accent) and sentence-initial adverbs that do not occur in the control condition (e.g. sì che, (invece) si). These polarity contrast markers are highlighted in bold face in Table 1. 
Table 2. Prosodic marking in polarity-switch context trials: Relative frequency of nuclear pitch accent placement (on the finite verb, on the non-finite verb if present, on the object) broken down by finite verb type (Lex, Aux, Cop) (percentages).

\begin{tabular}{llll}
\hline Nuclear accent placement & Lex & Aux & Cop \\
\hline Finite verb & 58.2 & 21.3 & 22.5 \\
Non-finite verb & n/a & 54.7 & n/a \\
Object & 41.8 & 24.0 & 77.5 \\
\hline
\end{tabular}

- Other markers (not specific to the assertion component or to polarity contrast): a nuclear pitch accent on the non-finite verb (in the case of analytical verb forms), a nuclear pitch accent on the object noun, the adverb invece.

Table 1 shows that in polarity-switch trials Italian speakers never produced lexical markers like the sentence-initial adverbs si che, (invece) sì. Prosodic marking accounted for the majority of the polarity-switch trials: verum focus accents in $34.3 \%$ and nuclear accents on the non-finite verb in $21.4 \%$ of all the polarity-switch cases. In the remaining trials, Italian speakers recruited forms that were also produced in predicate-focus contexts (control condition), namely, a nuclear accent on the object noun and the adverb invece.

The proportion of verum focus accents varied as a function of verb type; see Table 2, which shows that a verum focus accent was generally more often realized on lexical verbs than on auxiliary/copula verbs. To corroborate this observation, we ran a binomial logistic regression analysis (Baayen, 2008; Pinheiro and Bates, 2000) with NUCLEAR ACCENT ON THE FINITE VERB (Yes, No) as a function of VERB TYPE (Lex, Aux, Cop), adding SPEAKER and ITEM (specifically: speaker- and item-specific intercepts and slopes) as crossed random factors (Cunnings, 2012). The model confirmed that, compared to Lex, there were significantly fewer nuclear pitch accents on the finite verb in Aux $(\beta=-1.68$, $S E=0.34, t=-4.91, p<.0001)$ and in Cop $(\beta=-1.52, S E=0.37, t=-4.03, p<.0001)$, whereas the difference between Aux and Cop was not statistically significant $(p=.6)$.

We now turn to the phonological realization of the utterances containing a verum focus accent. The finite verb was mostly realized with a high-falling accent (i.e. $\mathrm{H}^{*}+\mathrm{L} n$ and $\mathrm{H}^{*} n$ in $92 \%$ of the verum focus accent trials). The nuclear accent was followed by downstepped post-nuclear accents in $79.9 \%$ of these cases (realized as ! $\mathrm{H}^{*}$ or $! \mathrm{H}^{*}+\mathrm{L}$ or $\mathrm{L}^{*}$ ) and by deaccented material in $20.1 \%$ (i.e. $\mathrm{L}-\mathrm{L} \%$ ). Figure 1 illustrates an example of verum focus accent, followed by a post-nuclear accent on the non-finite verb and on the object noun.

\section{Discussion}

Our data showed that about half of the polarity-switch contexts (44.3\%) were not produced differently from the predicate-focus contexts; in both conditions, the nuclear accent was realized on the object noun, which is the default position for nuclear pitch accents in Italian, and optionally accompanied by the adverb invece. In the remaining polarity-switch contexts, Italian speakers mainly recruited intonation: $34.3 \%$ of the 


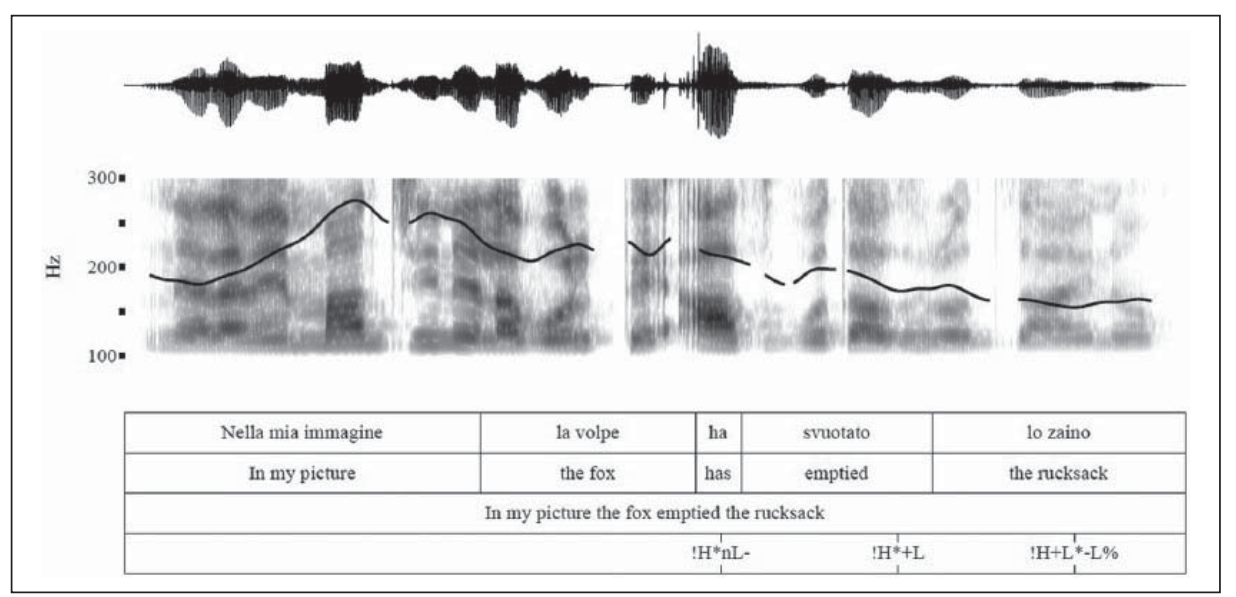

Figure I. Example pitch track of nuclear $\mathrm{H}^{*} n$ pitch accent on the auxiliary (ha 'has') followed by a post-nuclear accent on the non-finite verb (svuotato 'emptied') and on the object noun (lo zaino 'the rucksack'), spoken by a female speaker.

Notes. Tonal labelling (following Grice et al., 2005) is shown in the last tier. To direct attention to relevant accents, the tonal labelling does not include the prepositional phrase Nella mia immagine ('In my picture) and the grammatical subject noun in all the figures. Pitch contours are smoothed with a $10 \mathrm{~Hz}$ bandwidth.

polarity-switch trials carried a pitch accent on the finite verb (i.e. verum focus accent) and are thus considered instances of polarity contrast. Further $21.4 \%$ of the utterances with an auxiliary had a nuclear pitch accent on the non-finite verb. Neither type of prosodic contours was ever realized in the control predicate-focus contexts. Unlike verum focus, however, a nuclear accent on the non-finite verb does not specifically target the (affirmative) assertion/polarity component.

The absence of the sentence-initial constructions sì che or (invece) sì is in line with previous studies (Dimroth et al., 2010). Italian speakers rather produced the more neutral form invece. Since this adverb was also used in predicate-switch trials (control condition), it may serve to signal a general change of the topic situation (i.e. confederate: 'In my picture ...' vs. participant: 'In my picture on the other hand ...') than of the polarity (see Dimroth et al., 2010). Overall, we cannot exclude that the preference of intonational marking over lexical marking may be due to task-dependent effects: while speakers might feel more encouraged to use intonation when highlighting the contrast in a full utterance, lexical markers (and, in particular, the construction sì che) may be more frequent in combination with other syntactic configurations (e.g. elliptical structures; see Poletto and Zanuttini, 2013). On the other hand, it is also possible that the use of these lexical forms is more suitable in other pragmatic contexts (e.g. corrections). Future work will have to test these speculations and validate these findings by using other elicitation procedures and other baseline conditions (e.g. all-new or all-given sentences) to which the prosodic contours found in this study can be compared.

On the whole, our results clearly show that if encouraged to highlight a contrast in a more constraining set-up, Italian speakers adopt different types of encoding strategies (e.g. verum focus accent, nuclear accent on the non-finite verb). Such strategies do not 
have the same meaning contribution: of all the forms presented in Table 1, only the verum focus accents $(34.3 \%)$ can be treated as genuine markers of polarity contrast. When compared to German and Dutch natives, who encode polarity contrast in $83 \%$ and 95\% respectively (Turco et al., 2014; see also Appendix 1), the 34\% of verum focus accents suggests that polarity contrast may be less relevant for the purpose of common ground management in Italian. This assumption is strengthened by the percentages of nuclear accent placement across verb types. Nuclear accents on the finite verb occurred less frequently on lexically empty verbs (Aux, Cop), the carrier of the assertion component, than on lexically full verbs (Lex), in which assertion and semantic meaning are merged (see Bernini, 2009; Klein, 1998, 2006). If marking polarity contrast was more relevant, one would expect that Italian speakers would highlight it independent of verb type. It hence seems that structural constraints are ranked highly, so that the accentuation of a non-phrase final and monosyllabic function word is disfavoured (Selkirk 1995).

Next, the analysis of pitch accent types $\left(\mathrm{H}^{*} n\right.$ and $\left.\mathrm{H}^{*}+\mathrm{L} n\right)$ in verum focus accent cases confirms previous observations on (narrow) focus marking for Roman Italian (e.g. Frascarelli, 2004; Sardelli, 2006) and attests the presence of post-nuclear accents also for this regional variety, as found elsewhere (i.e. Bocci and Avesani, 2011; Grice et al., 2005).

To sum up, our findings show that polarity contrast is not consistently encoded in Italian. For a non-native speaker with German or Dutch as a mother tongue, Italian presents a rather heterogeneous input. The aim of the next experiment is to investigate whether in the same experimental setting German and Dutch non-native speakers of Italian consistently highlight the polarity, as they do in their L1s, or whether they have discovered that polarity marking is less systematic in Italian and that other meaning components may be highlighted.

\section{The acquisition of information structure marking in L2}

Previous studies on the acquisition of information structure marking (e.g. Carroll and Lambert, 2006; Carroll and von Stutterheim, 2003; von Stutterheim and Carroll, 2005) have shown that even if non-native speakers become better at mastering the L2 lexicon and grammar over time, they still have problems in adapting the structure of their utterances to the context and in obeying the discourse organizational principles of their targetlanguage. As a consequence, they may adopt (and adapt) the L2 structures for building up a discourse that follows the L1 patterns of information flow (i.e. 'discourse accent'; von Stutterheim, 2003). In this second study, we investigate the implications of the typological differences in polarity contrast marking for L2 productions. Evidence from Experiment 1 in Italian suggests that polarity-switch contexts are encoded less consistently, with marking strategies that may have different meaning contributions. By contrast, in the same experimental condition, the more consistent marking of polarity contrast in German (with verum focus accent) and in Dutch (with sentence-internal particles) respectively - see Appendix 1 - suggests that this pragmatic category is highly relevant for the information flow in these two languages (Turco et al., 2014). Given the differences between Italian on the one hand and German and Dutch on the other, we tested what German and Dutch non-native speakers of Italian do when encouraged to verbalize 
situations involving a polarity switch, and whether they would still highlight polarity contrast as frequently and in the same way as they are used to in their L1. In Experiment 2 , we investigated L1 transfer on three levels, the level of the relevance of a pragmatic category (i.e. how often polarity contrast is linguistically highlighted), the level of the linguistic realization (i.e. the prosodic and lexical markers recruited for encoding polarity contrast) and the level of phonetic implementation of phonological contrasts (actual realization of verum focus accent). On the basis of the findings from Experiment 1 and the studies reviewed above (see Section I), we predicted L1 transfer not only at a level of linguistic realization and phonetic implementation but also regarding the choice of the information structure unit to highlight (relevance of the pragmatic category).

\section{Experiment 2}

\section{Methods}

We replicated Experiment 1 with German and Dutch non-native speakers of Italian, using identical picture materials and the same confederate speaker.

a Participants. Fourteen German non-native speakers of Italian (4 male, 10 female, age range: $33-50$ years, age average $=41.3, S D=5.2)$ and 14 Dutch non-native speakers of Italian (5 male, 9 female, age range: $35-52$ years, age average $=47.3, S D=4.5$ ) participated in the study. All non-native speakers had received Italian language teaching at the university or language courses at colleges in the Netherlands and in Germany prior to the time of their residence in Italy (none of them started learning Italian before the age of 13). The mean period of stay in Italy was about 19 years for both the German non-native speakers $(10-28$ years, $S D=5.6)$ and the Dutch non-native speakers $(10-27$ years, $S D=$ 5.9).

To assess participants' L2 proficiency, non-native speakers performed a cloze test before the experiment (the Oxford written placement test for Italian). ${ }^{8}$ The Dutch nonnative speakers had an average score of 47.3 points (out of 52 points; $S D=3.1$ ), the German non-native speakers 48.8 points (out of 52 points, $S D=2.7$ ), so the distributions were clearly overlapping.

b Procedure. The elicitation procedure and recording conditions were similar to the Italian natives (Section III.1.c). The Dutch non-native speakers were tested in quiet rooms at the Koninklijk Nederlands Instituut Rome; the German non-native speakers at the Casa di Goethe and at the Deutsches Historisches Institut. All these institutions are located in Rome (Italy). Both groups of participants were living in Italy at the time of the testing.

c Data selection. Both data sets consisted of 448 items produced in polarity-switch contexts. We discarded 151 items from the Dutch data (disfluencies and hesitations: $n=45$, use of pronouns: $n=79$, different verb forms: $n=27$ ) and 137 items from the German data (disfluencies and hesitations: $n=39$, use of pronouns: $n=68$, other words: $n=30$ ). This left 297 items for the Dutch group (112 full lexical verbs, 100 auxiliary verbs, with 
Table 3. Polarity-switch context trials: Relative frequency of mutually exclusive linguistic markers employed by German and Dutch non-native speakers of Italian (percentages).

\begin{tabular}{llc}
\hline Linguistic markers & $\begin{array}{l}\text { German } \\
\text { non-natives }\end{array}$ & $\begin{array}{c}\text { Dutch non- } \\
\text { natives }\end{array}$ \\
\hline $\begin{array}{l}\text { Verum focus accent (with/without } \\
\text { postnuclear accents) }\end{array}$ & $\mathbf{7 2 . 3}$ & $\mathbf{5 1 . 2}$ \\
$\begin{array}{l}\text { Sentence-initial adverbs (i.e. sì che, (invece) si) } \\
\text { Sentence-internal intensifiers (e.g. proprio) }\end{array}$ & $\mathbf{4 . 8}$ & $\mathbf{5 . 7}$ \\
$\begin{array}{l}\text { Nuclear accent on the non-finite verb } \\
\text { Nuclear accent on the object (optionally with }\end{array}$ & 4.3 & $\mathbf{1 9 . 5}$ \\
the adverb invece) & 17.4 & 4.7 \\
\hline
\end{tabular}

Note. Polarity contrast markers are highlighted in bold.

85 copula verbs) and 311 for the German group (116 full lexical verbs, 110 auxiliary verbs, with 85 copula verbs). In the predicate-focus context trials, 150 German productions and 145 Dutch productions were discarded. The labelling procedure was the same as in Experiment 1.

\section{Results}

The interrater reliability score for nuclear pitch accent placement in polarity-switch contexts was found to be Kappa $=0.85(p<.0001), 95 \%$ CI $[0.65,0.95]$ for the German group and Kappa $=0.71(p<.0001), 95 \%$ CI $[0.35,1]$ for the Dutch group, suggesting a substantial agreement for both groups.

We first analysed how German and Dutch non-native speakers of Italian realized the predicate-focus utterances. Results showed that both non-native groups produced a pitch accent on the object noun in all the predicate-focus cases, just like the native Italian group. Moreover, more than $17 \%$ of these trials were accompanied by the adverb invece (German group: $17.5 \%$ of the cases; Dutch group: $21.2 \%$ of the cases), a realization that was also found in the Italian group.

We then analysed how polarity-switch trials were encoded by non-native speakers (Table 3) and compared the distribution of linguistic markers to that of Italian native speakers (Table 1). In addition to the categories used by native speakers, non-native speakers occasionally produced sentence-internal intensifiers like proprio, davvero (roughly meaning 'certainly'; see Section II). These items were hardly expected to occur in any of the contexts tested here (see Section III) and were indeed never produced by Italian natives (see Table 1). Conceivably, due to the lack of Italian (sentence-internal) particles equivalent to the Dutch WEL or the German DOCH/SCHON/WOHL (see Section I), non-native speakers may have adapted the intensifiers to signal polarity contrast (which can be encoded by particles in their mother tongues). We therefore treated such intensifiers as an extra-category of polarity marking. ${ }^{9}$

Compared to the frequency of occurrence of polarity markers in the Italian data (34.3\%), shown in Table 1, Table 3 shows that German and Dutch speakers of L2 Italian 
Table 4. Prosodic marking in polarity-switch context trials - Relative frequency of nuclear pitch accent located on the finite verb, on the non-finite verb, on the object, broken down by verb type (Lex, Aux, Cop) and L2 speaker group (German, Dutch) (percentages).

\begin{tabular}{|c|c|c|c|c|c|c|}
\hline \multirow{2}{*}{$\begin{array}{l}\text { Nuclear accent } \\
\text { placement }\end{array}$} & \multicolumn{3}{|c|}{ German non-natives } & \multicolumn{3}{|c|}{ Dutch non-natives } \\
\hline & Lex & Aux & Cop & Lex & Aux & Cop \\
\hline Finite & 73.4 & 69.0 & 75.0 & 50.5 & 40.0 & 75.0 \\
\hline Non-finite & $\mathrm{n} / \mathrm{a}$ & 13.0 & $\mathrm{n} / \mathrm{a}$ & $\mathrm{n} / \mathrm{a}$ & 10.8 & $\mathrm{n} / \mathrm{a}$ \\
\hline Object & 26.6 & 18.0 & 25.0 & 49.5 & 49.2 & 25.0 \\
\hline
\end{tabular}

highlight the polarity considerably more often. Table 3 further shows that the polarity contrast markers used by the L2 groups tend to reflect the linguistic encoding found in their L1s (see Turco et al., 2014). Although both non-native speaker groups mostly recruit verum focus accents, Dutch non-native speakers show a slightly higher preference for sentence-internal intensifiers (probably reflecting the high proportion of WEL in their L1) compared to the German group.

To statistically validate these differences, we calculated a multinomial logistic regression analysis (Bates and Sarkar, 2007; Jaeger, 2008) with LINGUISTIC MARKER as dependent variable and LANGUAGE GROUP as fixed factor (three levels). The results confirmed that compared to the Italian native group, German and Dutch non-native speakers produced significantly more verum focus accents $\left(\beta_{\text {German }}=1.66, S E=0.20, t=8.30, p<.0001\right.$; $\left.\beta_{\text {Dutch }}=1.23, S E=0.20, t=6.06, p<.001\right)$, more sentence-initial adverbs $\left(\beta_{\text {German }}=3.59\right.$, $\left.S E=1.04, t=3.43, p<.0001 ; \beta_{\text {Dutch }}=3.68, S E=1.04, t=3.53, p<.0001\right)$, more sentence-internal intensifiers $\left(\beta_{\text {German }}=2.27, S E=1.12, t=2.01, p<.05 ; \beta_{\text {Dutch }}=4.91, S E=\right.$ $1.02, t=4.80, p<.0001)$, and fewer nuclear accents on the non-finite verb $\left(\beta_{\text {German }}=\right.$ $\left.-0.70, S E=0.34, t=-2.05, p<.05 ; \beta_{\text {Dutch }}=-0.66, S E=0.33, t=-1.99, p<.05\right)$. Moreover, compared to the Dutch group, German non-native speakers produced significantly more verum focus accents $(\beta=0.42, S E=0.21, t=1.96, p<.05)$ and significantly fewer sentence-internal intensifiers $(\beta=-2.63, S E=0.55, t=-4.78, p<.0001)$, whereas no differences were found for the other categories (all $p$-values $>.8$ ).

Given the main effect of verb type on the distribution of nuclear pitch accents on the finite verb in Italian natives (Table 2), we tested whether those differences also held for L2 speakers (Table 4). From Table 4 we can observe that the location of the nuclear accent is affected by verb type and language group (i.e. within the Dutch group there are fewer nuclear accents on the finite verb in conditions Aux and Lex). A binomial logistic regression analysis with NUCLEAR ACCENT (Yes, No) as dependent variable and LANGUAGE GROUP and VERB TYPE as fixed factors shows an interaction between verb type and language group $(p<.05)$ : Specifically, there was an effect of verb type for the Dutch group (Cop vs. Aux: $\beta=-1.28, S E=0.55, t=-2.30, p<.05$; Cop vs. Lex: $\beta=-1.06, S E=0.55$, $t=-1.90, p=.05$ ) but not for the German group (all $p$-values $>.2$ ). At first glance, the fact that the Dutch group produced more nuclear accents in Cop than in the other verb types is surprising. It is possible, however, that there is a trade-off between the use of intonation and particles. Specifically, it was speculated that lexical markers are produced more often with full content verbs than with light verbs. A related case is found for 
English do (which is used with lexical verbs). To test this assumption, we computed a binomial model on the Dutch data with LEXICAL MARKER as dependent variable (Yes, No) and VERB TYPE as fixed factor. To this end, the cases shown in Table 3 were recoded as binary variable: the cases in the first row did not contain a lexical marker; the cases in the second and third row did. Results showed an effect of verb type: compared to Cop, Lex was more often combined with lexical markers $(\beta=1.11, S E=0.58, t=1.92, p=.05)$, whereas there was no difference between Aux and Cop $(p>.1)$. This analysis corroborates a trade-off between the two kinds of linguistic markings and partly explains the effect of verb type in the Dutch group.

Two examples of typical verum focus accents produced by German non-native speakers and Dutch non-native speakers are shown in Figures 2a and 2b. Regarding the phonetic implementation of verum focus accents, we analysed how both non-native groups encoded post-focal constituents and, in particular, whether these constituents were realized as downstepped post-nuclear accents as in native Italian. The phonetic analysis revealed that German and Dutch non-native speakers deaccented post-focal material in $96.4 \%$ and $90.8 \%$ of the verum focus accent cases, respectively, whereas Italian natives did so in only $20.1 \%$ of the cases (cf. Experiment 1). These data suggest an intonational foreign accent.

\section{Discussion}

Experiment 2 showed clear differences in the linguistic marking of polarity-switch contexts between Italian natives on the one hand and German and Dutch non-native speakers of Italian on the other. As expected, despite their comparatively long residence in Italy (19 years on average), non-native speakers produced polarity contrast markers (i.e. verum focus accents and lexical markers like adverbs and intensifiers) significantly more frequently than Italian natives. This difference suggests that non-native speakers still show traces of the organizational principles operating in their L1s, namely, orienting their information flow around the polarity component. In particular, they recruited L2 surface markers that are not used in the target language for this purpose (e.g. sentence-internal intensifiers like proprio) or that are less frequently produced (i.e. verum focus accent). These findings extend previous investigations on the L2-encoding of information structure at a discourse level (e.g. von Stutterheim, 2003). However, while earlier studies have shown effects of L1 transfer on information organization in language external domains like space and time (e.g. Carroll and Lambert, 2006; Hendricks and Hickmann, 2011), our findings show that L1 transfer in high-proficient non-native speakers' productions can also affect common ground management involving language-specific concepts like polarity.

Turning now more specifically to the transfer of linguistic marking, most of the differences between non-native and native speakers may be attributed to effects of transfer from their L1s. For instance, Dutch non-native speakers recruited - even though occasionally - sentence-internal intensifiers like proprio ('certainly') that were never produced by Italian speakers in the same contexts, thereby reflecting a preference for expressing polarity contrast lexically, as is done in Dutch (Turco et al., 2014). Similarly, L1 transfer may account for the high occurrence of verum focus accents produced by German non-native 


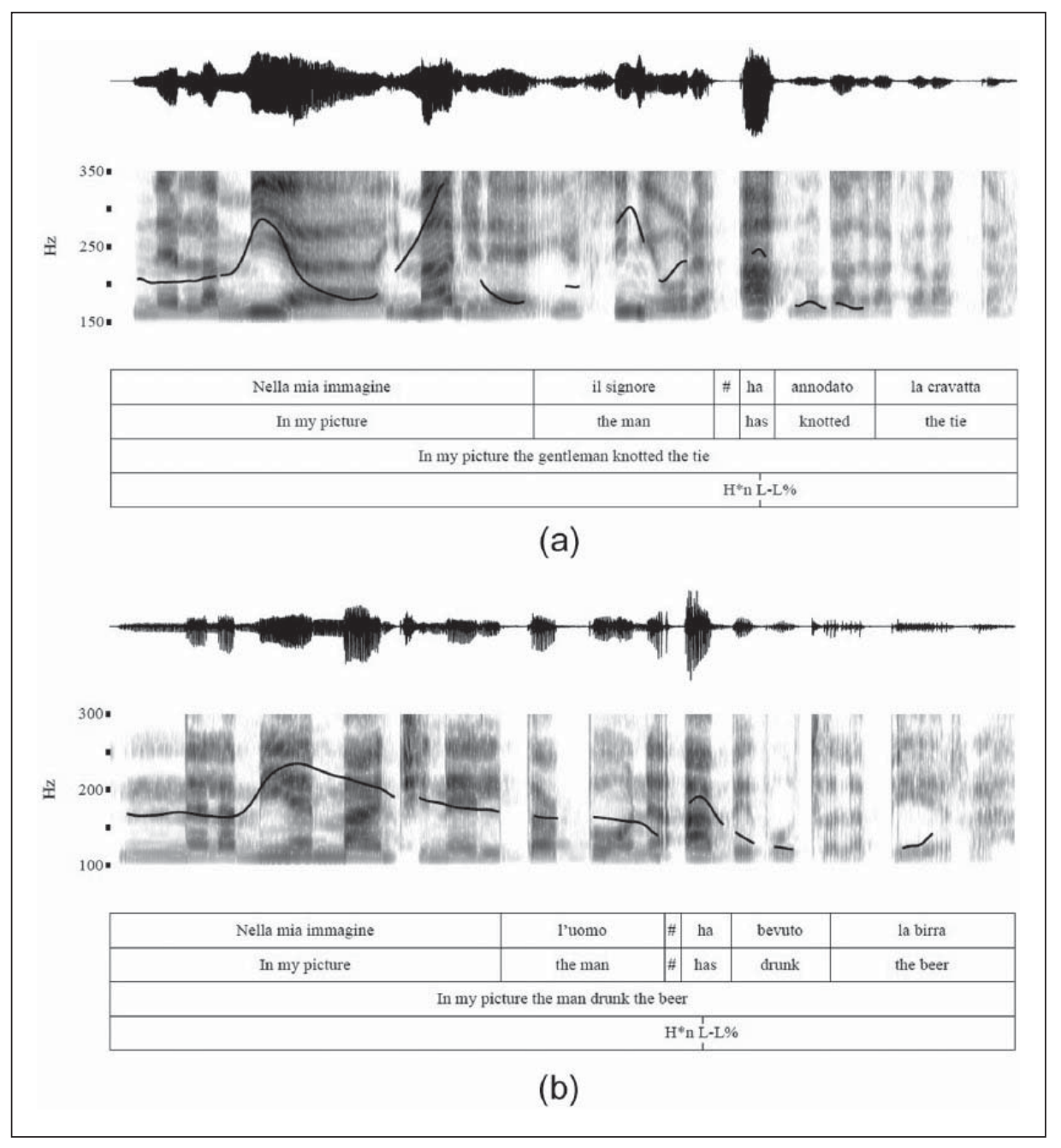

Figure 2. Example pitch tracks of nuclear accent placement $\left(\mathrm{H}^{*} \mathrm{n}\right)$ on the auxiliary verb (ha 'has'), followed by unaccented materials, spoken by a German (panel a) and Dutch (panel b) non-native speaker of Italian.

Note: Tonal labelling (following Grice et al., 2005) is only shown for the nuclear accent.

speakers when compared to the Italian and the Dutch group, thus mirroring what German natives do in comparable contexts (Turco et al., 2014).

Clear differences between native speakers and the two non-native speaker groups were also found with respect to the placement of the nuclear accent in utterances with different verb types. Despite the fact that focused auxiliary/copula verbs tend to be procliticized to the following lexical word in Italian and are therefore hardly accented (Experiment 1), both non-native speaker groups accented the finite verbs more frequently 
than Italian natives. German non-native speakers even produced nuclear pitch accents on finite verbs equally often in all verb types (i.e. lexical or auxiliary/copula verbs), in accordance with their L1. Previous work (Turco et al., 2013, 2014) shows that in polarity-switch contexts focused auxiliary/copula verbs can be promoted to prosodic words in German (i.e. they appear in strong form) and consequently receive a pitch accent. German non-native speakers seem to transfer this rule into their L2 (for L1 transfer of focus projection rules, see Zubizaretta and Nava, 2011 and references therein). Dutch speakers, on the other hand, showed more verum focus accents than expected from their L1 productions (see discussion below).

Finally, transfer was also found to affect the phonetic implementation of verum focus accents by German and Dutch non-native speakers. Non-native speakers deaccented post-focal constituents following contrastively accented finite verbs more frequently than Italian natives, which is in line with how a contrastive accent is (typically) phonetically implemented in their L1s. The close correspondence between information status of referents (giveness) and deaccentuation is indeed a wellattested phenomenon in Germanic languages (i.e. Baumann, 2006 for German; Swerts et al., 2002 for Dutch). These data hence lend further support for the role of phonetic transfer in L2 intonational phonology (e.g. He et al., 2011; Mennen, 2004; Rasier and Hiligsmann, 2007).

What cannot be accounted for by L1 transfer is the high percentage of verum focus accents produced by Dutch non-native speakers of Italian (51.2\%), which were never produced in similar contexts in their L1. A possible explanation is that accents on the finite verb (the polarity/assertion operator) are a typical pattern in 'assertion-oriented' languages (Dimroth et al., 2010). The verum focus accent productions by both L2 speaker groups seem to reflect the common underlying trait between German and Dutch regarding the relevance of polarity contrast for common ground management. Like Germans, Dutch native speakers accent finite verbs for expressing a closely related semantic meaning (see Gussenhoven, 1999). More specifically, in Dutch a nuclear pitch accent on the finite verb (and without particle) expresses a 'counterpresuppositional' meaning (see also Dimroth et al., 2010; e.g. speaker A: He READS books in reply to speaker B: If he read books, he would know this, taken from Gussenhoven, 1999: 52). This may explain why Dutch non-native speakers used a familiar marking (i.e. verum focus accent) that in their L1 has a very similar function. The significantly higher proportion of verum focus accents on copula verbs compared to other verb types in the Dutch non-native data was explained by a smaller number of lexical markers in that condition. In other words, the two kinds of polarity markers verum focus accents and lexical markers appear to compete with each another (Keller and Alexopoulou, 2001). The fact that Dutch non-native speakers tend to realize verum focus accents more frequently on copula verbs, the carrier of the assertion component, stays in line with the 'assertion-oriented' hypothesis.

\section{Conclusions and outlook}

We investigated the acquisition of pragmatic categories that are encoded less frequently and less consistently in the target than in the native language. We therefore tested how 
affirmative polarity contrast (i.e. a focus on the polarity of an utterance in contexts where speakers assert a claim that was previously denied) is expressed by high-proficient German and Dutch non-native speakers of Italian, compared to Italian natives.

Experiment 1 showed that Italian speakers encoded polarity contrast with a verum focus accent (i.e. a pitch accent on the finite verb) in 34.3\%. When comparing the distribution of verum focus accents across lexical verbs and auxiliary/copula verbs, we found that the type of finite verb affected focus-projection in Italian: there were significantly more nuclear accents on lexical finite verbs $(58 \%$ of the polarity switch contexts) than on auxiliary/copula verbs (about $22 \%$ of the polarity switch contexts). It is thus possible that structural constraints (i.e. avoiding a pitch accent on non-phrase final and monosyllabic function word) are ranked higher than discourse and pragmatic constraints (i.e. accenting auxiliary/copula verbs, the carriers of the assertion component; see Klein 1998, 2006). In other words, verb type seems to matter more than finiteness and assertion, a situation similar to what we found for French (Turco et al., 2013). From a typological perspective, our data strongly support prior findings that polarity contrast is not as consistently encoded in Italian as in German or Dutch (Turco et al., 2014). Further evidence on the minor relevance of polarity contrast in Italian is provided by the few occurrences of the sentence-initial adverb invece. Given that this form also occurred in the control condition (i.e. predicate-focus context trial), it seems to indicate a general change of the topic situation (i.e. confederate: 'In my picture ...' vs. participant: 'In my picture on the other hand ...') than of the polarity (Dimroth et al., 2010). What Italian speakers never produced in our experiment was either the form si che - most likely to be reserved for corrections (Poletto and Zanuttini, 2013) - or (invece) si - claimed to indicate a change of the topic along with the polarity (Dimroth et al., 2010) and which non-native speakers produced in a few occasions. We assume that sentence-initial adverbs may be too 'assertive' in the tested contexts for natives, a hypothesis that will be tested in future studies.

Experiment 2 investigated the implications of such typological differences on productions by high-proficient L2 speakers. Our data showed that German and Dutch nonnative speakers encoded polarity-switch contexts by producing verum focus accents far more frequently than Italian natives. Furthermore, sentence-internal intensifiers (e.g. proprio) - unattested in Italian - were also occasionally recruited for highlighting the polarity. These findings suggest that non-native speakers transferred the relevance of polarity contrast for the discourse flow and largely also their L1 linguistic marking. Finally, in line with previous studies, they transferred the phonetic implementation of a verum focus accent, more likely to be followed by deaccented post-focal constituents than by post-nuclear accents.

Taken together, our findings suggest that the overt marking produced by non-native speakers is guided by the organizational principles that are part of their (L1) linguistic knowledge. Previous studies (Carroll and Lambert, 2006; von Stutterheim, 2003) have shown that non-native speakers were not able to refrain from applying their L1 organizational principles when involved in complex discourse tasks such as film-retellings. In the current study, we showed that non-native speakers transferred their L1 principles already at the utterance-level, with a task that was cognitively not very demanding. At this point, it is interesting to speculate about the pragmatic consequences of such mismatches in common ground management: Would non-natives sound 'too assertive' to native speakers' ears? 


\section{Acknowledgements}

We wish to thank Tilman Harpe for drawing the picture stimuli and the German and Dutch institutions Koninklijk Nederlands Instituut Rome, Casa di Goethe, Deutsches Historisches Institut. We also wish to thank the Università della Sapienza in Rome for helping us in recruiting participants, and the anonymous reviewers for their helpful comments on earlier versions of this article.

\section{Declaration of conflicting interest}

The authors declare that there is no conflict of interest.

\section{Funding}

This research is part of a $\mathrm{PhD}$ project of the first author funded by the ANR-DFG project 'LANGACROSS' (DI 808/1-2, awarded to Christine Dimroth). This research was also supported by the Max Planck Institute for Psycholinguistics (Nijmegen, The Netherlands), which offered technical support and research facilities.

\section{Notes}

1. In this article we adopt the term 'contrast' and treat it interchangeably with that of 'focus'. Solving the long-standing theoretical definitional problems concerning these two notions would go beyond the scope of this article. For discussion on this issue, the interested reader is referred to Krifka and Musan (2012).

2. By 'common ground' we mean information that is mutually shared in a communicative situation. By 'common ground management' we refer to the information flow that speakers organize according to their communicative needs and goals (see, for instance, Krifka and Musan, 2012).

3. Capitals indicate the presence of accent.

4. See also other work on the encoding of information structure in Italian (e.g. Brunetti et al., 2010; D'Imperio and Cangemi, 2011).

5. But see Gili Fivela (2002) for the prosodic realization of broad focus and contrastive focus in Pisa Italian.

6. It was not possible to find more than 8 copula pictures that could be easily and unambiguously depicted.

7. The second annotator was a native speaker of German with a strong background on Italian phonology and phonetics. She had to decide whether the nuclear accent was located either on the finite verb or on the complement in Lex condition, either on the finite or on the nonfinite verb or on the grammatical object in Aux condition, either on the copula verb or on the predicative noun phrase in Cop condition.

8. This test is available online http://www.lang.ox.ac.uk/courses/tst placement italian.html (accessed the 8th of March, 2015).

9. It can be argued that the adverb invece could also be treated as a marker of polarity in learner varieties. However, only the intensifiers were considered as polarity markers. Different from the sentence-initial adverb invece, intensifiers showed a syntactic and prosodic behaviour similar to the ones of the Germanic affirmative particles, that is, they were located after the finite verb and were mostly accented.

\section{References}

Antinucci F and Cinque G (1977) Sull'ordine delle parole in italiano: l'emarginazione [On word order in Italian]. Studi di grammatica italiana 6: 121-46. 
Atterer M and Ladd DR (2004) On the phonetics and phonology of 'segmental anchoring' of F0: evidence from German. Journal of Phonetics 32: 177-97.

Baayen RH (2008) Analyzing linguistic data: A practical introduction to statistics using $R$. Cambridge: Cambridge University Press.

Bates DM and Sarkar D (2007). lme4: Linear mixed-effects models using S4 classes. R package version $0.9975-12$.

Baumann S (2006) The intonation of givenness: Evidence from German: Volume 508. Tübingen: Niemeyer.

Belletti A (2009) Structures and strategies. New York: Routledge.

Benazzo S, Andorno C, Interlandi G, and Patin C (2012) Perspective discursive et influence translinguistique: Exprimer le contraste d'entité en français et en italien L2 [Discourse perspectives and cross-linguistic influence: Expressing contrast of entities in French and Italian as L2s]. LIA 3-2:173-201.

Benincà P (1993) Sintassi. In: Sobrero A (ed.) Introduzione all'italiano contemporaneo. Le strutture. Volume 1. Roma-Bari: Laterza, 247-90.

Benincà P, Salvi G, and Frison L (1988) L'ordine degli elementi della frase e le costruzioni marcate [Word order and marked constructions]. In: Renzi L, Salvi G, and Cardinaletti A (eds) Grande grammatica Italiana di consultazione: Volume 1. Bologna: Il Mulino, 129-239.

Bernini G (1995) Le profrasi [Pro-sentences]. In: Renzi L, Salvi G, and Cardinaletti A (eds) Grande grammatica Italiana di consultazione: Tipi di frase, deissi, formazione delle parole: Volume 3. Bologna: Il Mulino, 175-222.

Bernini G (2009) Constructions with preposed infinitive: Typological and pragmatic notes. In: Lunella M (ed.) Information structure and its interfaces. Berlin: Mouton de Gruyter, 105-28.

Bocci G (2014) The syntax-prosody interface: A cartographic perspective with evidence from Italian. Amsterdam/Philadelphia, PA: John Benjamins.

Bocci G and Avesani C (2011) Phrasal prominences do not need pitch movements: Postfocal phrasal heads in Italian. Proceedings of the 12th Annual Conference of the International Speech Communication Association (Interspeech), Florence, Italy, 1357-60.

Boersma P and Weenink D (2012) Praat: Doing phonetics by computer: Version 5.3.34 [website]. Amsterdam. Retrieved from: http://www.praat.org (March 2015).

Brunetti L, D'Imperio M, and Cangemi F (2010) On the prosodic marking of contrast in Romance sentence topic: Evidence from Neapolitan Italian. Proceedings of the 5th International Conference on Speech Prosody, 100202: 100201-04. Chicago, IL. Retrieved from http:// speechprosody2010.illinois.edu/papers/100202.pdf (March 2015).

Carroll M and Lambert M (2006) Reorganizing principles of information structure in advanced L2s: a study of French and German learners of English. In: Byrnes H, Weger-Guntharp H, and Sprang K (eds) Educating for advanced foreign language capacities: Constructs, curriculum, instruction, assessment. Washington, DC: Georgetown University Press, 54-73.

Carroll M and von Stutterheim C (2003) Typology and information organisation: Perspective taking and language specific effects in the construal of events. In: Giacolone Ramat A (ed.) Typology and second language acquisition. Berlin: Mouton de Gruyter, 365-402.

Carroll M, Murcia-Serra J, Watorek M, and Bendiscioli A (2000) The relevance of information organization to second language acquisition studies. Studies in Second Language Acquisition 22: 441-66.

Caspers J and van der Wouden T (2008) Modal particles in Dutch as a second language: Evidence from a perception experiment. Linguistik Online 44: 121-30.

Cohen J (1960) A coefficient of agreement for nominal scales. Educational and Physiological Measurement 20: 37-46. 
Cunnings I (2012) An overview of mixed-effects statistical models for second language researchers. Second Language Research 28: 369-82.

D'Imperio M (2001) Focus and tonal structure in Neapolitan Italian. Speech Communication 33: $339-56$.

D'Imperio M (2002) Italian intonation: An overview and some questions. Probus 14: 37-69.

Dimroth C, Andorno C, Benazzo S, and Verhagen J (2010) Given claims about new topics: How Romance and Germanic speakers link changed and maintained information in narrative discourse. Journal of Pragmatics 42: 3328-44.

Face LT and D'Imperio M (2005) Reconsidering a focal typology: Evidence from Spanish and Italian. Italian Journal of Linguistics 17: 271-89.

Farnetani E and Zmarich C (1997) Prominence patterns in Italian: An analysis of F0 and duration. Proceedings of the ESCA Workshop on Intonation: Theory, Models and Applications, Athens, Greece, 115-18.

Féry C and Samek-Lodovici V (2006) Focus projection and prosodic prominence in nested foci. Language 82: 131-50.

Frascarelli M (2004) L'interpretazione del focus e la portata degli operatori sintattici [The interpretation of focus and the scope of syntactic operators]. In: Albano Leoni F, Cutugno F, Pettorino M, and Savy R (eds) Il Parlato Italiano: Atti del Convegno Nazionale (Napoli, 13-15 febbraio 2003). Napoli: M. D'Auria Editore - CIRASS, CD-ROM B06.

Gili Fivela B (2002) Tonal alignment in two Pisa Italian peak accents. Proceedings of the 1st International Conference on Speech Prosody, Aix-en-Provence, France, 339-42.

Giordano R (2004) Aspetti strutturali e interrelazioni contestuali dell'intonazione dell'italiano: analisi prosodica di due dialoghi delle varietà di Roma e di Perugia [Structural aspects and contextual interrelations on Italian intonation: Prosodic analyses of two dialogues on varieties spoken in Rome and Perugia]. Unpublished doctoral dissertation, Università degli Studi di Perugia, Italy.

Grice M, D'Imperio M, Savino M, and Avesani C (2005) Strategy for intonation labelling across varieties of Italian. In: Jun S-A (ed.) Prosodic typology: The phonology of intonation and phrasing. Oxford: Oxford University Press, 362-89.

Gussenhoven C (1999) On the limits of focus projections in English. In: Bosch P and van der Sandt R (eds) Focus: Linguistic, cognitive, and computational perspectives. Berlin: Foris, 43-55.

Gut U (2009) Non-native speech: A corpus-based analysis of phonological and phonetic properties of L2 English and German. Frankfurt am Main: Peter Lang.

He X, van Heuven VJ, and Gussenhoven C (2011) Phonetic implementation must be learnt: Native versus Chinese realization of focal accent in Dutch. Proceedings of the 17th International Congress of Phonetic Sciences, Hong Kong, 843-46.

Hendricks H and Hickmann M (2011) Space in second language acquisition. In: Cook V and Bassetti B (eds) Language and bilingual cognition. Hove: Psychology Press, 315-39.

Hirschberg J and Avesani C (1997) The role of prosody in disambiguating potentially ambiguous utternaces in English and Italian. Proceedings of the ESCA Workshop on Intonation: Theory, Models and Applications, Athens, Greece, 189-92.

Hogeweg L, de Hoop H, Ramachers S, van der Slik F, and Wottrich V (in press) The L2 acquisition of the German particle doch. International Review of Applied Linguistics (IRAL) in Language Teaching.

Jaeger TF (2008) Categorical data analysis: Away from ANOVAs (transformation or not) and towards logit mixed models. Journal of Memory and Language 59: 434-46.

Keller F and Alexopoulou T (2001) Phonology competes with syntax: experimental evidence for the interaction of word order and accent placement in the realization of information structure. Cognition 79: 301-72. 
Kelm OR (1987) An acoustic study on the differences of contrastive emphasis between native and non-native Spanish speakers. Hispania 70: 627-33.

Klein W (1998) Assertion and finiteness. In: Dittmar N, Penner Z, and Weissenborn J (eds) Issues in the theory of language acquisition: Essays in honor of Jürgen Weissenborn. Bern: Lang, $225-45$.

Klein W (2006) On finiteness. In: Van Geenhoven V (ed.) Semantics in acquisition. Dordrecht: Kluwer, 245-72.

Klein W (2008) The topic situation. In: Ahrenholz B, Bredel U, Klein W, Rost-Roth M, and Skiba R (eds) Empirische Forschung und Theoriebildung: Beiträge aus Soziolinguistik, Gesprochene-Sprache- und Zweitspracherwerbsforschung: Festschrift für Norbert Dittmar zum 65. Geburtstag. Frankfurt am Main: Peter Lang, 287-306.

Krifka M and Musan R (2012) Information structure: Overview and linguistic issues. In: Krifka M and Musan R (eds) The expression of information structure: Volume: The Expression of Cognitive Categories (ECC). Berlin: Mouton de Gruyter, 1-44.

Ladd DR (2008) Intonational phonology: Volume 119. 2nd edition. Cambridge: Cambridge University Press.

Landis JR and Koch GG (1977) The measurement of observer agreement for categorical data. Biometrics 33: 159-74.

Matić D and Wedgwood D (2013) The meanings of focus: The significance of an interpretationbased category in cross-linguistic analysis. Journal of Linguistics 49: 127-63.

McGory TJ (1997) Acquisition of intonational prominence in English by Seoul Korean and Mandarin Chinese speakers. Unpublished doctoral dissertation, Ohio State University, Ohio, USA.

Mennen I (2004) Bi-directional interference in the intonation of Dutch speakers of Greek. Journal of Phonetics 32: 543-63.

Möllering M (2001) Teaching German modal particles: A corpus-based approach. Language Learning and Technology 5: 130-51.

Möllering M and Nunan D (1995) Pragmatics in interlanguage: German modal particles. Applied language learning 6: 41-64.

Nespor M and Vogel I (1986) Prosodic phonology. Dordrecht: Foris.

Nguyên TA-T, Ingram CLJ, and Pensalfini JR (2008) Prosodic transfer in Vietnamese acquisition of English contrastive stress patterns. Journal of Phonetics 36: 158-90.

Pinheiro JC and Bates DM (2000) Mixed-effects models in S and S-PLUS. New York: Springer.

Poletto C and Zanuttini R (2013) Emphasis as reduplication: Evidence from sì che/no che sentences. Lingua 128: 124-41.

R Development Core and Team (2012) $R$ : A language and environment for statistical computing: Version 2.15.0. Austria: The R Foundation for Statistical Computing. Retrieved from: http:// www.r-project.org (March 2015).

Rasier L and Hiligsmann P (2007) Prosodic transfer: Theoretical and methodological issues. Nouveaux cahiers de linguistique Française 28: 41-66.

Rizzi L (1997) The fine structure of the left periphery. In: Haegeman L (ed.) Elements of grammar: Volume: Handbook of generative syntax. Dordrecht: Kluwer Academic, 281-337.

Rooth M (1996) Focus. In: Lappin S (ed.) The handbook of contemporary semantics theory. London: Blackwell, 271-97.

Sardelli E (2006) Prosodiatopia: Alcuni parametri acustici per il riconoscimento del parlante [A few acoustic parameters for the identification of the speaker's accent]. Unpublished doctoral dissertation, Università di Pisa, Italy.

Selkirk E (1995) The prosodic structure of function words. In: McCarthy JJ (ed.) Optimality theory in phonology: A reader. Oxford: Blackwell, 464-82. 
Swerts M, Krahmer E, and Avesani C (2002) Prosodic marking of information status in Dutch and Italian: A comparative analysis. Journal of Phonetics 30: 629-54.

Swerts M and Zerbian S (2010) Prosodic transfer in Black South African English. Proceedings of the fifth International Conference on Speech Prosody 2010, Chicago, USA, 100198:100191100194.

Truckenbrodt H (1999) On the relation between syntactic phrases and phonological phrases. Linguistic Inquiry 30: 219-55.

Turco G, Braun B, and Dimroth C (2014) When contrasting polarity, the Dutch use particles, Germans intonation. Journal of Pragmatics 62: 94-106.

Turco G, Dimroth C, and Braun B (2013) Intonational means to mark Verum focus in German and French. Language and Speech 56: 461-91.

Turco G, Gubian M, and Schertz J (2011) A quantitative investigation of the prosody of Verum Focus in Italian. Proceedings of the 12th Annual Conference of the International Speech Communication Association (Interspeech 2011), Florence (Italy), 961-64.

Ueyama M and Jun S-A (1998) Focus realization in Japanese English and Korean English intonation. In: Akatsuka N, Hoji H, Iwasaki S, Sohn S-O, and Strauss S (eds) Japanese/Korean linguistics: Volume 7. Standford, CA: CSLI, Stanford University Press, 629-45.

von Stutterheim C (2003) Linguistic structure and information organization: The case of very advanced learners: Volume 3. Amsterdam: John Benjamins.

von Stutterheim C and Carroll M (2005) Subjektwahl und Topikkontinuität im Deutschen und Englischen [The choice of grammatical subjects and the expression of topic continuity in German and English]. Zeitschrift für Literaturwissenschaft und Linguistik 139: 7-28.

von Stutterheim C and Lambert M (2005) Cross-linguistic analysis of temporal perspectives in text production. In: Hendricks H (ed.) The structure of learner varieties. New York: De Gruyter, 203-30.

Zubizaretta ML and Nava E (2011) Encoding discourse-based meaning: Prosody vs. syntax: Implications for second language acquisition. Lingua 121: 652-69. 


\section{Appendix I}

Table 5. Polarity-switch context trials: Relative frequency of linguistic markers employed by German and Dutch native speakers (percentages).

\begin{tabular}{lcc}
\hline Linguistic markers & German natives & Dutch natives \\
\hline Verum focus & $\mathbf{8 2 . 7}$ & $\mathbf{0 . 0}$ \\
sentence-internal affirmative & $\mathbf{0 . 0}$ & $\mathbf{9 4 . 8}$ \\
particles (e.g. WEL) & & \\
nuclear accent on the non-finite verb & 0.0 & 2.2 \\
nuclear accent on the object & 17.3 & 3.0 \\
\hline
\end{tabular}

Note. Polarity contrast markers are highlighted in bold.

Source. Data from Turco et al., 2014.

\section{Appendix 2}

Context negation utterances spoken by the confederate speaker on the basis of artwork pictures.

\section{Lexical condition}

1. Nella mia immagine il sindaco non taglia il nastro. In my-F.SG picture the-M.SG mayor not cut-PRES-3SG the-M.SG ribbon 'In my picture the mayor doe NEG cut the ribbon.'

2. Nella mia immagine il gallo non lancia il boomerang. In my-F.SG picture the-M.SG rooster NEG launch-PRES-3SG the-M.SG boomerang 'In my picture the rooster does not launch the boomerang.

3. Nella mia immagine il gorilla non rompe la noce di cocco. In my-F.SG picture the-M.SG gorilla NEG break-PRES-3SG the-F.SG coconut 'In my picture the gorilla does not break the coconut.'

4. Nella mia immagine il bambino non gira la clessidra. In my-F.SG picture the-M.SG child NEG turn-PRES-3SG the-F.SG hourglass 'In my picture the child does not turn the hourglass.'

5. Nella mia immagine il cobra non morde il cavallo. In my-F.SG picture the-M.SG cobra NEG bite-PRES-3SG the-M.SG horse 'In my picture the cobra does not bite the horse.'

6. Nella mia immagine il giocatore non calcia la palla. In my-F.SG picture the-M.SG football player NEG kick-PRES-3SG the-F.SG ball 'In my picture the football player does not kick the ball.'

7. Nella mia immagine il calabrone non punge il maiale. In my-F.SG picture the-M.SG bumble-bee NEG sting-PRES-3SG the-M.SG pig 'In my picture the bumble-bee does not sting the pig.'

8. Nella mia immagine il soldato non preme il grilletto. In my-F.SG picture the-M.SG soldier NEG pull_on-PRES-3SG the-M.SG trigger 'In my picture the soldier does not pull the trigger on.'

9. Nella mia immagine l'uomo non legge il giornale. In my-F.SG picture the-M.SG man NEG read-PRES-3SG the-M.SG paper 'In my picture the man does not read the paper.' 
10. Nella mia immagine l'uomo non fuma la sigaretta. In my-F.SG picture the-M.SG man NEG smoke-PRES-3SG the-F.SG cigarette 'In my picture the man does not smoke the cigarette.'

11. Nella mia immagine la donna non lava i pantaloni. In my-F.SG picture the-F.SG woman NEG wash-PRES-3SG the-M PL trousers 'In my picture the woman does not wash the trousers.'

12. Nella mia immagine il bambino non mangia il panino. In my-F.SG picture the-M.SG child NEG eat-PRES-3SG the-M.SG sandwich 'In my picture the child does not eat the sandwich.'

\section{Auxiliary condition}

1. Nella mia immagine l'elefante non ha sfondato il pavimento. In my-F.SG picture the-M.SG elephant NEG has-PERF-3SG broken-PTCT the-M.SG floor 'In my picture the elephant has not broken the floor.'

2. Nella mia immagine il ragazzo non ha bucato la ruota. In my-F.SG picture the-M.SG boy NEG has-PERF-3SG punched-PTCT the-F.SG wheel 'In my picture the boy has not punched the wheel.'

3. Nella mia immagine la bambina non ha strappato la banconota. In my-F.SG picture the-F.SG child NEG has-PERF-3SG torn-PTCT the-F.SG banknote 'In my picture the child has not torn the banknote.'

4. Nella mia immagine la volpe non ha svuotato lo zaino. In my-F.SG picture the-F.SG fox NEG has-PERF-3SG emptied-PTCT the-M.SG rucksack 'In my picture the fox has not emptied the rucksack.'

5. Nella mia immagine il bambino non ha mangiato le caramelle. In my-F.SG picture the-M.SG child NEG has-PERF-3SG eaten-PTCT the-PL.SG candies 'In my picture the child has not eaten the candies.'

6. Nella mia immagine la signora non ha raccolto il fiore. In my-F.SG picture the-F.SG lady NEG has-PERF-3SG picked-PTCT the-M.SG flower 'In my picture the lady has not picked the flower.'

7. Nella mia immagine l'uccello non ha svegliato la guardia. In my-F.SG picture the-M.SG bird NEG has-PERF-3SG wakened_up-PTCT the-F.SG guard 'In my picture the bird has not wakened up the guard.'

8. Nella mia immagine il macellaio non ha tagliato la carne. In my-F.SG picture the-M.SG butcher NEG has-PERF-3SG cut-PTCT the-M.SG meat 'In my picture the man has not cut the meat.'

9. Nella mia immagine l'uomo non ha bevuto la birra. In my-F.SG picture the-M.SG man NEG has-PERF-3SG drunk-PTCT the-F.SG beer 'In my picture the man has not drunk the beer.'

10. Nella mia immagine il signore non ha annodato la cravatta. In my-F.SG picture the-M.SG gentlmen NEG has-PERF-3SG tied-PTCT the-F.SG tie 'In my picture the gentleman has not tied the tie.'

11. Nella mia immagine il boscaiolo non ha abbattuto l'albero. In my-F.SG picture the-M.SG woodsman NEG has-PERF-3SG hacked-PTCT the-M.SG tree 'In my picture the woodsman has not hacked the tree up.'

12. Nella mia immagine il poliziotto non ha arrestato il ladro. In my-F.SG picture the-M.SG policeman NEG has-PERF-3SG arrested-PTCT the-M.SG robber 'In my picture the policeman has not arrested the robber.' 


\section{Copula condition}

1. Nella mia immagine la donna non è sbalordita.

In my-F.SG picture the-F.SG woman NEG is-PRES-3SG astonished 'In my picture the woman is not astonished.'

2. Nella mia immagine l'uomo non è impaurito. In my-F.SG picture the-M.SG man NEG is-PRES-3SG scared 'In my picture the man is not scared.'

3. Nella mia immagine la donna non è assonnata. In my-F.SG picture the-F.SG woman NEG is-PRES-3SG sleepy 'In my picture the woman is not sleepy.'

4. Nella mia immagine l'uomo non è raffreddato. In my-F.SG picture the-M.SG man NEG is-PRES-3SG sick 'In my picture the man is not sick.'

5. Nella mia immagine la donna non è affamata. In my-F.SG picture the-M.SG man NEG is-PRES-3SG hungry 'In my picture the woman is not hungry.'

6. Nlla mia immagine la donna non è arrabbiata. In my-F.SG picture the-F.SG woman NEG is-PRES-3SG upset 'In my picture the woman is not upset.'

7. Nella mia immagine l'uomo non è disgustato. In my-F.SG picture the-M.SG man NEG is-PRES-3SG disgusted 'In my picture the man is not disgusted.'

8. Nella mia immagine l'uomo non è innamorato. In my-F.SG picture the-M.SG man NEG is-PRES-3SG in love 'In my picture the man is not in love.' 